\title{
Samambaias e licófitas do Estado de Pernambuco, Brasil: Metaxyaceae
}

\author{
Iva Carneiro Leão Barros ${ }^{1}$ \\ Augusto César Pessoa Santiago ${ }^{2}$ \\ ${ }^{1}$ Universidade Federal de Pernambuco, Departamento de Botânica \\ Avenida Prof. Moraes Rego, s/n ${ }^{\circ}$, Cidade Universitária, CEP 50670-900, Recife - PE, Brasil \\ ${ }^{2}$ Universidade Federal de Pernambuco, Centro Acadêmico de Vitória \\ Núcleo de Biologia, Laboratório de Biodiversidade \\ Autor para correspondência \\ ivaclb@gmail.com
}

Submetido em 16/03/2010

Aceito para publicação em 18/06/2010

\section{Resumo}

O presente trabalho é parte da Flora das samambaias e licófitas ocorrentes no estado de Pernambuco. Metaxyaceae é nativa no estado e está representada por uma única espécie, Metaxya rostrata (Kunth) C. Presl. Descrições, ilustrações e comentários sobre a distribuição geográfica e habitats são apresentados.

Unitermos: Floresta Atlântica, Metaxya, pteridófitas

\section{Abstract}

Ferns and lycophytes of Pernambuco State, Brazil: Metaxyaceae). The present paper elucidates part of the fern flora of Pernambuco State. Metaxyaceae is native to the state and is represented by a single species, Metaxya rostrata (Kunth) C. Presl. Descriptions and illustrations, as well as geographical distribution and habitats, are presented.

Key words: Atlantic forest, ferns, Metaxya

\section{Introdução}

Metaxyaceae apresenta distribuição Neotropical, sendo constituída por um único gênero, Metaxya $\mathrm{C}$. Presl., com ocorrência no sul do México, América Central, Pequenas Antilhas, Trinidad, Colômbia, Venezuela, Guianas, Equador, Peru, Bolívia e Brasil (Riba, 1995). O gênero está representado por duas espécies, Metaxya rostrata (Kunth) C. Presl e M. lanosa A. R. Sm. \& H. Tuomisto, a última registrada somente para a região amazônica na Venezuela e Peru (Smith et al., 2001).
Segundo dados moleculares, Metaxyaceae está relacionada com grupos de samambaias arborescentes, formando um clado ("tree ferns") com Thyrsopteridaceae, Culcitaceae, Plagiogyriaceae, Loxomataceae, Cyatheaceae, Cibotiaceae e Dicksoniaceae, sendo grupo irmão desta última (Schuettpelz e Pryer, 2008). Os autores citam que não existe uma sinapomorfia morfológica conhecida que justifique tal clado, o que pode justificar a dificuldade de enquadramento destas famílias em sistemas de classificação mais antigos, como discutido em Tryon e Tryon (1982). 
O objetivo deste trabalho é fornecer informações sobre a família Metaxyaceae em Pernambuco, contribuindo com o projeto que visa apresentar uma monografia das famílias de samambaias e licófitas para o estado.

\section{Material e Métodos}

O presente estudo segue a padronização apresentada por Barros e Santiago (2007), dentro do projeto "Pteridófitas do estado de Pernambuco". Considerando a atual classificação das plantas vasculares sem sementes (ver Ranker e Haufler, 2008), utilizaram-se os termos "samambaias e licófitas" no presente estudo.

A padronização dos termos segue a obra de Lellinger (2002).

O presente estudo é baseado nas coletas realizadas pelos autores nas últimas décadas e nas coleções depositadas nos principais herbários regionais: UFP, PEUFR, IPA, MAC, JPB, EAN e HEAC (siglas de acordo com Thiers, 2010).

\section{Resultados e Discussão}

Metaxyaceae Pic. Serm., Webbia 24 (2): 701.1970.

\section{Metaxya C. Presl, Tent. Pterid.: 59. 1836.}

Plantas terrestres ou rupícolas, raramente epífitas; rizoma robusto, reptante a subereto, sifonostélico, densamente piloso no ápice, sem escamas; tricomas septados, conspícuos, amarelados a alaranjados; frondes monomórficas, cespitosas a fasciculadas; pecíolos contínuos com o rizoma, com um feixe vascular na base; lâminas 1-pinadas, pina terminal conforme, glabras ou esparsamente pubescentes sobre as vênulas e tecido laminar; venação aberta, vênulas simples ou às vezes bifurcadas; soros na face abaxial da lâmina, 1-3 (5) por vênula, irregularmente dispostos, com paráfises; indúsio ausente; esporângios com pedicelos curtos, anel oblíquo; esporos triletes, tetraédricos, globosos, sem clorofila.

No estado de Pernambuco a família é representada por uma espécie, a saber:
1.1. Metaxya rostrata (Kunth) C. Presl, Tent. Pterid. 59. 1836. (Figuras 1-3)

Plantas terrestres; rizoma decumbente a ereto, 7-15mm diâm., com muitos tricomas filiformes e tortuosos, castanho-claros a amarelados; frondes eretas ou escandentes até $2 \mathrm{~m}$ de compr.; pecíolos até $1,04 \mathrm{~m}$ de compr., castanho-claros, sulcados na face adaxial, tricomas na base; lâminas 1-pinadas, cartáceas, glabras a esparsamente pubescentes, tricomas castanho-claros a amarelados, raque sulcada na face adaxial; pinas lanceoladas a elípticas, até $35 \mathrm{~cm}$ compr. e $5 \mathrm{~cm}$ larg., 6-16 de cada lado, pecioluladas, base cuneada, assimétrica, ápice variando de agudo ou acuminado a caudado, por vezes, truncado, margens inteiras a serreadas no ápice; vênulas paralelas entre si, simples ou às vezes bifurcadas; soros arredondados a elípticos, alaranjados quando jovens, irregularmente distribuídos na face abaxial, sem indúsio, paráfises presentes; esporângio subséssil, com anel oblíquo interrompido pelo pedicelo.

Material selecionado: BRASIL. Pernambuco: Cabo de Santo Agostinho, Reserva Ecológica de Gurjaú, Córrego do Zabé, 14/VIII/1991, I. C. L. Barros \& E. R. Fonseca s. n. (UFP 8377); Mata do Café, 10/VII/1991, E. R. Fonseca \& K. Porto s. n. (UFP 8360); 10/VII/1991, I. C. L. Barros \& E. R. Fonseca s. n. (UFP 8258); 14/ VIII/1991, I. C. L. Barros \& E. R. Fonseca s. n. (UFP 8372, UFP 8377); 15/IV/2003, M.R. Pietrobom \& A. F. N. Pereira s. n. (UFP 41784); 14/IV/2003, A.C.P. Santiago \& A. F. N. Pereira s. n. (UFP 41783).

Material adicional examinado: BRASIL. Paraíba: Mamanguape, Cachoeira do Rio das Pratas (Rio Vermelho), A. Santiago, R.A. Pontes \& M.J. Lima 933, 30/X/2004, (UFP); Bahia: Una, Reserva Biológica do Mico Leão, M.A. Amorim et al. 1912, 24/I/1996 (CEPEC); ibid., S.C. de Sant'ana et al. 347, 28/VII/1993 (CEPEC).

Distribuição Geográfica: Sudeste do México até o Panamá, Guadalupe, Trinidad, da Colômbia até as Guianas, Equador, Peru, Bolívia e Brasil (região Amazônica, Paraíba, Pernambuco e Bahia).

As espécies de Metaxya crescem geralmente em florestas úmidas e lugares sombreados, sendo comumente encontradas em áreas de baixas altitudes, 


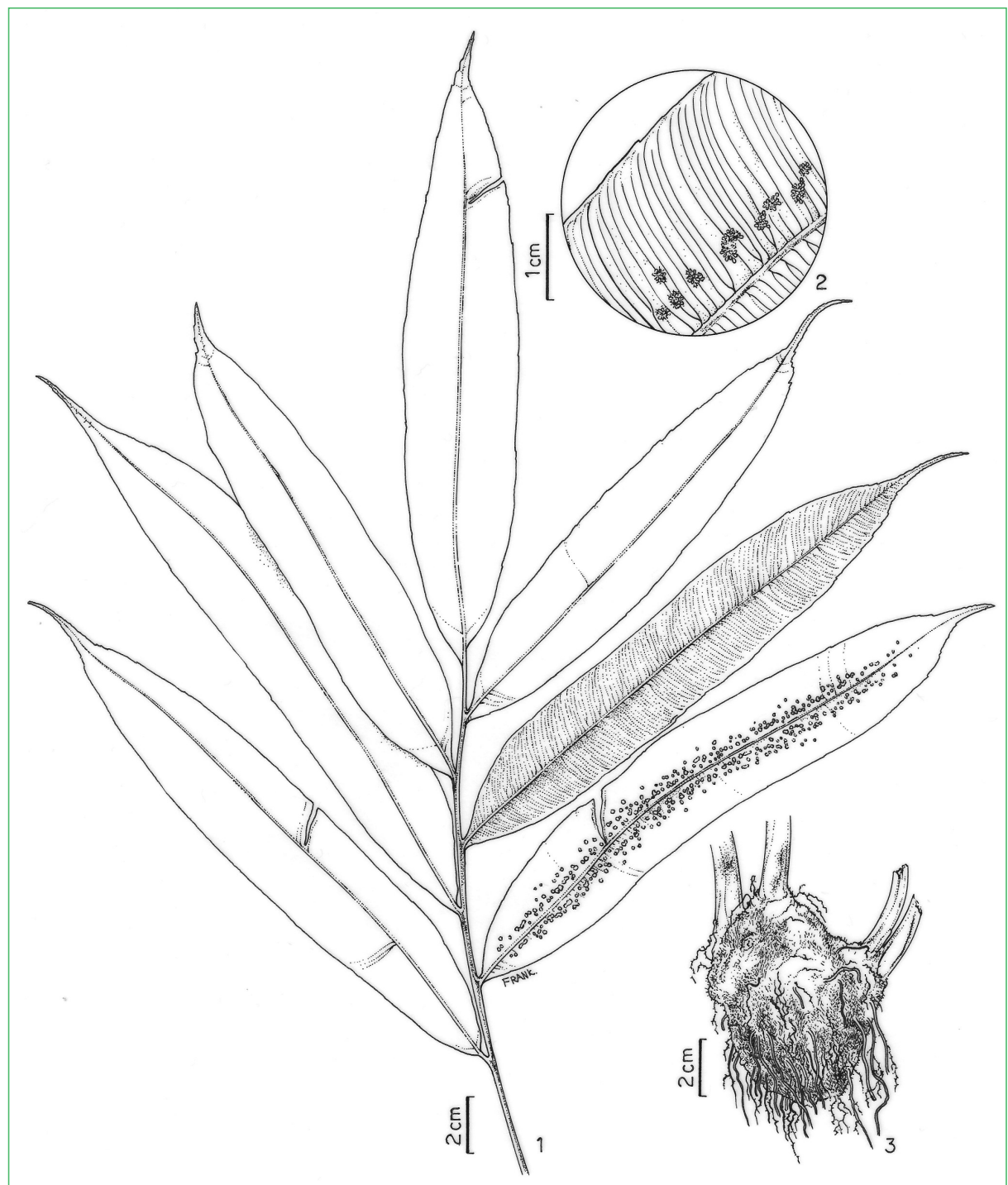

FIGURAS 1-3: Metaxya rostrata (Kunth) C. Presl (I. C. L. Barros \& E. R. Fonseca s.n.,UFP 8377); 1. Parte apical de uma fronde fértil. 2. Detalhe de pina fértil, evidenciando os soros e o padrão de venação. 3. Aspecto geral do rizoma.

ocorrendo desde o nível do mar até 750m (Tryon e Tryon, 1982; Smith et al., 2001; Auxiliadora e Prado 2005). Segundo Smith et al. (2001), Metaxya lanosa pode ser distinguida de $M$. rostrata por apresentar densa pilosidade no pecíolo e na raque, com tricomas longos e enrolados, pelas pinas longo-pecioluladas na parte distal da fronde, pela lâmina espessa e de textura coriácea, entre outras características.

Em Pernambuco, Metaxya rostrata ocorre sempre como terrícola, geralmente em solo lamacento ou úmido no interior da mata, muitas vezes em áreas de encosta. A espécie foi registrada apenas na Reserva Ecológica de Gurjaú, e não é muito frequente nos fragmentos florestais da Reserva. A espécie corre sério risco de extinção local, devido à ocorrência restrita e pela ação antrópica evidente na Reserva, onde se calcula que nos últimos 30 anos, mais de $25 \%$ da área de floresta já foi perdida (G. Borges e K. Pôrto, dados não publicados).

\section{Agradecimentos}

Ao CNPq pela Bolsa de Produtividade em Pesquisa (processo 3023224/04-6), concedida ao primeiro autor e aos revisores pelas importantes sugestões. 


\section{Referências}

Auxiliadora, M. S. C.; Prado, J. 2005. Flora da Reserva Ducke, Amazonas, Brasil: Pteridophyta - Metaxyaceae. Rodriguesia, 56 (86): 72-73.

Barros, I. C. L.; Santiago, A. C. P. 2007. Pteridófitas do Estado de Pernambuco, Brasil: Psilotaceae. Bradea, XII: 17-23.

Lellinger, D. B. 2002. A modern multilingual glossary for taxonomic pteridology. Pteridologia, 3A: 1-262.

Ranker, T. A.; Haufler, C. H. (Eds). 2008. Biology and evolution of ferns and lycophytes. Cambridge University Press, New York, USA, 480pp.

Riba, R. 1995. Metaxyaceae. Moran, R.C. \& R. Riba, R. (Eds.). Flora Mesoamericana. 1. Psilotaceae a Salviniaceae. Universidad Nacional Autónoma de México, Ciudad de México, México, p.8586.
Schuettpelz, E.; Pryer, K. M. 2008. Fern phylogeny. In: Ranker, T. A. \& Haufler, C. H. (Eds.). Biology and evolution of ferns and lycophytes. Cambridge University Press, New York, USA, p.395415.

Smith, A. R..; Tuomisto, H.; Pryer, K. M.; Hunt; J. S.; Wolf, P. G. 2001. Metaxya lanosa a second species in the genus and fern family Metaxyaceae. Systematic Botany, 26 (3): 480-486.

Thiers, B. 2010. [continuously updated]. Index Herbariorum. A global directory of public herbaria and associated staff. New York Botanical Garden's Virtual Herbarium. http://sweetgum.nybg.org/ ih/. Acesso em 26 de maio de 2010.

Tryon, R. M.; Tryon, A. F. 1982. Ferns and allied plants, with special reference to Tropical America. Springer-Verlag, New York, USA, 857pp. 